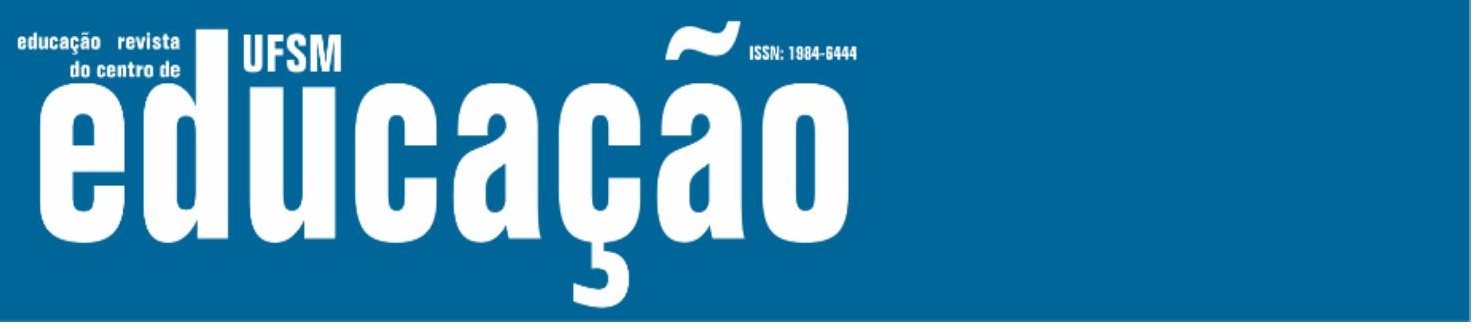

ISSN: 1984-6444 | http://dx.doi.org/10.5902/1984644440327

\title{
O direito à escolarização de crianças e adolescentes com doenças crônicas no Brasil: uma análise a partir do pensamento complexo e da teoria crítica
}

The right of education of children and youth with chronic diseases in Brazil: an analysis from the complex thoughts and critical theory

Francisca Maria Sousa

Secretaria de Educação do Estado do Piauí, Teresina, Piauí, Brasil. cineidesousa@yahoo.com.br-000.0002.9332-9686

Maria Celeste Ramos Silva

Secretaria Municipal de Educação, Salvador, Bahia, Brasil. mariacelesteramos@hotmail.com-0000-0002-5224-3069

Recebido em 02 de outubro de 2019

Aprovado em 27 de janeiro de 2020

Publicado em 20 de março de 2020

\section{RESUMO}

O empreendimento deste artigo tem como objetivo dar ênfase sobre o processo de escolarização de crianças e adolescentes com doenças crônicas no Brasil. Consideramos que o impacto do adoecimento crônico e os prejuízos associados à doença, podem (in)visibilizar sua participação e protagonismo no espaço escolar e por conseguinte na sociedade. Muitos estudos sobre a experiência do adoecimento crônico, na perspectiva socioantropológica nas últimas décadas, se intensificaram no Brasil valendo-se de referenciais de experiência que privilegiam o ponto de vista das pessoas em suas narrativas, contrapondo-se à concepção biomédica. Nesse sentido, para este empreendimento, nos valeremos das concepções da teoria crítica e da complexidade. Ao recorremos tais concepções, foi possível considerar que, tanto as marcas que (in)visibilizam crianças adolescentes com doenças crônicas na escola, são também as que colocam seus familiares/cuidadores, assim como professores em condições desiguais de exclusão e humilhação social, sob a ordem do preconceito e discriminação. Na mesma medida que nos aponta para a necessidade de maior aprofundamento no que se refere às possibilidades e aos desafios sofridos cotidianamente, mas principalmente e efetivamente sobre seus direitos e amparo à vida escolar, do mesmo modo que indica maior responsabilidade do Estado para ampliação das políticas públicas de amparo e proteção social à esse público.

Palavras-chave: Doença crônica; Escolarização infanto-juvenil e hospitalização; Complexidade; Direito. 


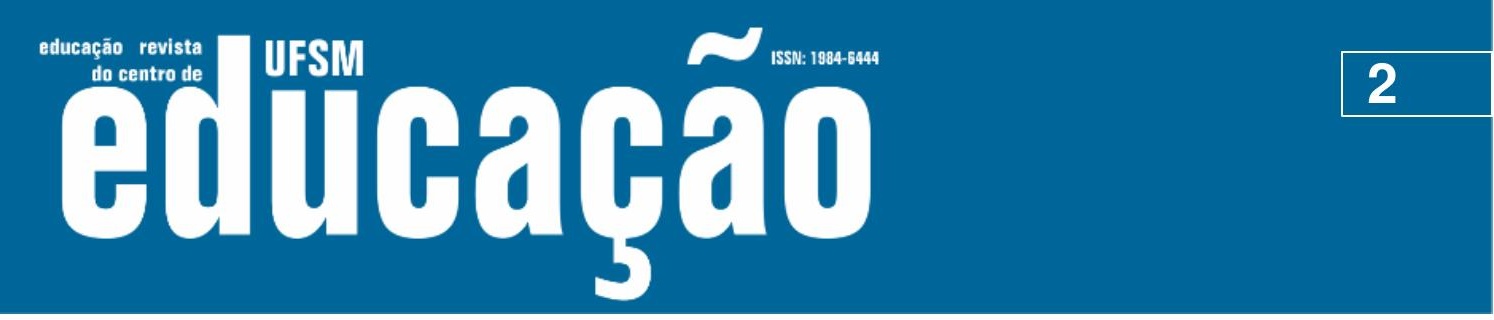

ISSN: 1984-6444 | http://dx.doi.org/10.5902/1984644440327

\section{ABSTRACT}

The purpose of this article is to emphasize the education process of children and youths with chronic diseases in Brazil. We realize that the impact of chronic disease and its damage on children and youths can harm their participation and leadership in schools and consequently in the society. Many studies about experiences of chronic illness on the socio-anthropological perspective in the last decades have intensified in Brazil by using the experience and point of view of the people in their narratives, in contrast to the biomedical conception. In this sense, for this project, we used the concepts of critical theory and complexity. In the same way that it points us to the need for a deeper understanding of the possibilities and challenges faced daily, but mainly and effectively about their rights and support for school life, just as it indicates a greater responsibility of the State for the expansion of policies public protection and social protection to this public.

Keywords: Infanto-juvenil; Schooling and hospitalization; Complexity; Right.

\section{Introdução}

A proposição para elaborar esse artigo advém do nosso interesse como pesquisadoras nesta área, onde atuamos como professoras e voluntárias no hospital e acompanhamos o processo de escolarização de crianças e adolescentes em situação de hospitalização vivendo com doenças crônicas (anemia falciforme, asma, renal crônico, lúpus, HIV/Aids, câncer, diabetes), fossem por curto período ou tempos mais prolongados.

No que se refere ao acompanhamento do processo educacional desses educandos, ao experimentarem uma situação de hospitalização e adoecimento, a Classe Hospitalar ${ }^{1}$, atuou e ainda atua como dispositivo político de ressignificação e/ou continuidade ao processo de escolarização regular destes. Quando se fala da criança e adolescente hospitalizado, afirma-se numa pedagogia da atenção e cuidado à:

Criança hospitalizada, inclusive no que se refere à escolarização, vem produzir um certo estranhamento ao hospital, mas também à escola, ambos necessários à integralização da atenção hospitalar e da educação da criança. A escolarização constitui o mais potente agenciamento da subjetividade (excluída a família) na sociedade contemporânea e a manutenção do encontro pedagógico-educacional favorece a construção subjetiva de uma estabilidade de vida (não como elaboração psíquica da enfermidade e da hospitalização, mas como continuidade e segurança 


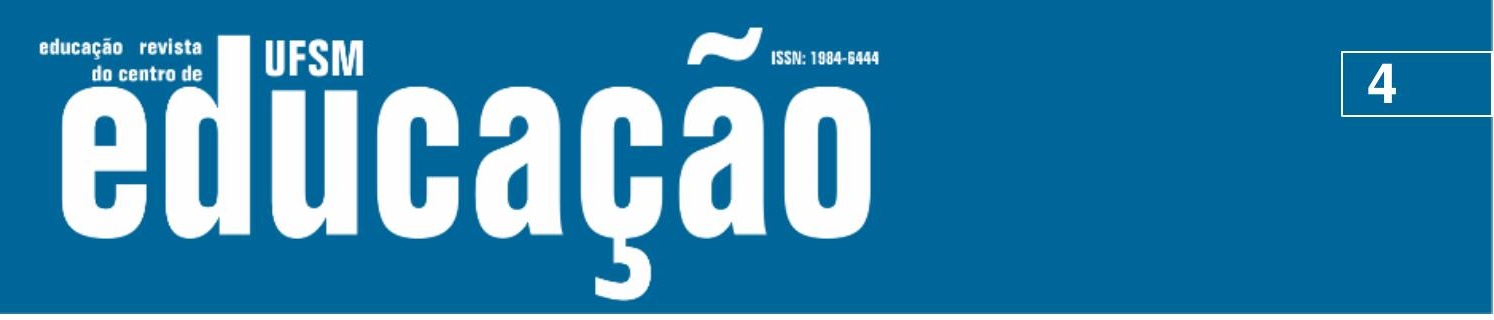

ISSN: 1984-6444 | http://dx.doi.org/10.5902/1984644440327

nas diretrizes curriculares para a educação básica. Do mesmo modo configura-se como desafio às estruturas governamentais no sentido de considerar legitima a organização das Classes Hospitalares.

Para este empreendimento, elegemos fundamentos que constituem complementariedade, o que nos permite dialogar com o pensamento de Edgar Morin e Bourdieu. Expressamente, o nosso interesse cercou-se das interpretações teóricas apresentadas na teoria crítica, das noções da teoria da complexidade e do cotidiano da escola na experiência com o adoecimento crônico, principalmente das doenças do sangue, como o HIV/Aids, anemia falciforme, talassemia, entre outras. Isso, em razão das características próprias do processo de escolarização dos educandos e cronicidade, suas interações e concepções, ou melhor, como sinalizam as condições de se conviver com alguém nestas circunstâncias ou mesmo dessa possibilidade, nas dimensões entre o vivido e o vir-a-ser (o devir).

De igual maneira nos interessamos pelo destaque das exigências docentes sob a égide da ideologia escolar levando em consideração três aspectos: o afastamento da escola, que acarreta absenteísmo; o adoecimento crônico e as investidas no processo de escolarização.

Tendo como premissa a importância da educação escolar para propiciar às gerações instrumentos de efetiva participação social e considerando o domínio do acervo de conhecimentos e técnicas acumuladas pela humanidade, a ação pedagógica supõe organização, sistematização e controle. Fundamentalmente, quando olhamos "a evolução da escola ao longo de um século, constatamos que a célula básica permanece intacta (a classe) perdura, mas ao redor desse nó central multiplicaram-se grupos mais e mais complexos" (TARDIF e LESSARD, 2007, p 81). Com efeito, (op. Cit), como 'grupo de referência' na escola, os professores nunca chegaram a controlar seu ambiente organizacional nem a impor suas normas de trabalhos aos outros, executam suas tarefas na "linha de fogo" da produção e participam pouco da gestão e do controle da organização da instituição. Entretanto, no espaço micro da sala de aula, é o professor quem administra e controla fisicamente os estudantes, no forte sentido do termo, nas suas necessidades, não apenas nos corredores da escola que são invadidos pelos problemas que afligem a 


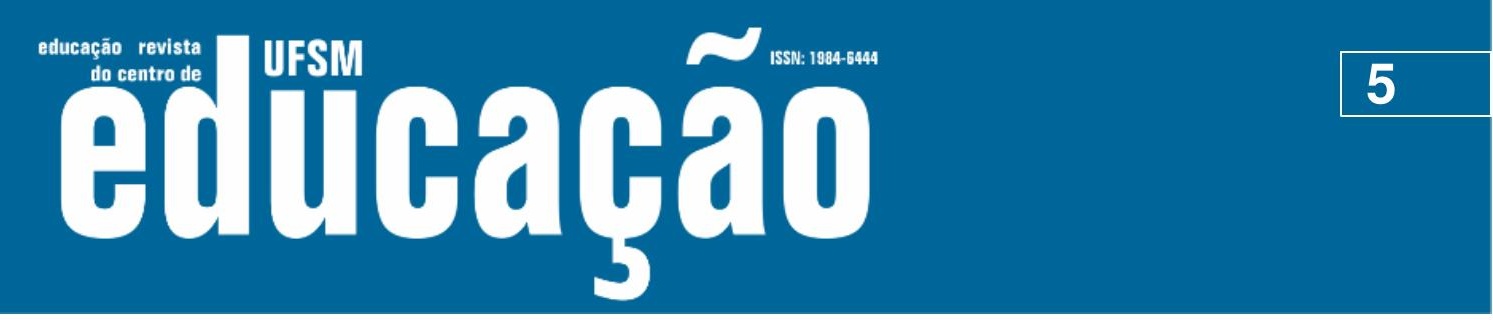

ISSN: 1984-6444 | http://dx.doi.org/10.5902/1984644440327

sociedade (violência, drogas entre outros), mas, sobretudo, são eles um dos principais responsáveis por apresentar respostas favoráveis às atividades cognoscitivas dos escolares, assim como considerar o conteúdo das novas pautas que se desdobram das políticas sociais, neste caso, a inclusão em sentido ampliado na saúde e na educação.

\section{Adoecimento crônico e seus impactos no processo da escolarização}

A trajetória de vida da pessoa com doença crônica é marcada por intercorrências que inevitavelmente repercutem nas atividades cotidianas. Segundo Canesqui (2010), a doença crônica é um conceito da sociedade ocidental que se refere às condições de saúde que podem ser gerenciadas, mas não curadas, apresentando sintomas contínuos ou periódicos que interferem em várias dimensões da vida do adoecido e no seu entorno. Esta autora afirma, ainda, através das palavras de Strauss que:

[...] as doenças crônicas são de longa duração, incertas, múltiplas, desproporcionalmente intrusivas e requerem paliativos porque são incuráveis. Essas características são essenciais para pensar nos impactos sobre os pacientes, famílias e profissionais de saúde. (STRAUSS et al, 1984 apud CANESQUI, 2007, p. 21).

Embora não exista um consenso entre os autores acerca do conceito de doença crônica na infância, optamos, neste artigo, por aquele destacado por Silva (2001) como o mais aceito na atualidade. A doença crônica:

[...] [É] uma desordem de base biológica, cognitiva e psicológica, que traz seqüelas[sic] como limitação de função ou atividade, ou prejuízo nas relações sociais, quando comparadas com outras crianças saudáveis da mesma idade, tanto em nível físico, cognitivo, emocional e de desenvolvimento em geral; dependência de medicação, tecnologia médica, aparelhos específicos e assistência pessoal; necessidade de cuidados médicos, psicológicos ou educacionais especiais, ou ainda de acomodações diferenciadas em casa e na escola. (SILVA, 2001, p.30).

Estudos sobre a repercussão deste tipo de condição na vida social da criança, do adolescente e de seus familiares revelam, dentre outros aspectos, dificuldades de ordem física, emocional, social, econômica. Tanto pesquisas que abordam de modo geral implicações da doença crônica, quanto àquelas que dão foco às especificidades, como por exemplo, as que tratam de crianças e 


\section{- Tusm Ellthapao

ISSN: 1984-6444 | http://dx.doi.org/10.5902/1984644440327

Desse modo, não podemos olvidar sobre o possível desconhecimento social das verdadeiras intenções das políticas públicas na atenção à saúde do escolar. É importante destacar que a discriminação na escola pode assumir muitas formas, operacionalmente o modo ofensivo não os alcança na ocorrência direta por uma palavra "mal dita", mas Ihes chega sob a mais grave, a nosso ver, pela indiferença, por meio da diferenciação no tratamento e na investida no processo de sua escolarização. O direito de receber tratamento igual, ou seja, a não discriminação, é um dos aspectos dos direitos humanos. Decerto, ninguém deve ser tratado de maneira diferente e negativa com base nas suas diferenças, sejam quais forem, entretanto esta é uma das contradições vividas pela escola na contemporaneidade.

Ross (2000, p. 50) afirma que o discurso da escola inclusivista apresenta exigências pela respeitabilidade às diferenças e necessidades individuais, significa um avanço, pois visa estender-se a todos, contudo este discurso "torna explícito seu caráter idealista, abstrato e descontextualizado, na medida em que postula o aumento da solidariedade entre as pessoas, como decorrência da simples convivência entre elas". Evidencia-se pois, que mesmo estando dentro da escola estes sujeitos podem experimentar tanto o processo de integração quanto 0 de segregação (que se configura na própria exclusão), modelos institucionais pensados já superados pela sociedade.

\section{A prática pedagógica no espaço hospitalar: a partir do diálogo sobre o pensamento complexo no âmbito da educação e saúde}

No Brasil, tanto a Educação quanto a Saúde vêm construindo aproximações significativas no cumprimento do âmbito das suas missões e do seu papel social, por intermédio dos avanços das políticas públicas desenvolvidas em torno dos respectivos campos, sendo que os mesmos se configuram por meio de articulação entre projetos integrados. É nessa perspectiva de integração que discutiremos a relação entre Educação e Saúde, uma vez que, nos sentimos desafiados a adentrarmos no contexto do hospital enquanto educadores atuantes, ou que ainda irão atuar no contexto da escolarização hospitalar. 


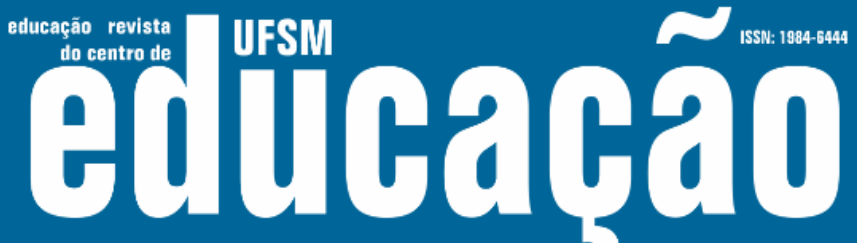

ISSN: 1984-6444 | http://dx.doi.org/10.5902/1984644440327

orquestradores da operacionalização de políticas públicas efetivamente consistentes e promotoras de uma educação e saúde como áreas constituintes de uma expressiva relevância para a qualidade da vida humana e do planeta.

\section{Considerações}

É fato que o silenciamento e a (in)visibilidade aos processos de escolarização, por parte da sociedade e da escola, acarreta certos prejuízos ao escolar com doença crônica. Acreditamos, entretanto, que trazer o assunto e outros temas a ela relacionado para o cenário da escola, não implica constranger ou fragilizar, mas afirmar o cuidado necessário como direito. Por mais simples que seja da nossa parte, todo empenho para explicar as bases de processamento complexo dos sistemas de exclusão em uma sociedade ou instituição, seria insuficiente, melhor dizendo, quase inútil, pois ela funda-se em bases ideológicas distintas, produzidas sócio historicamente. Daquilo já foi dito, consideramos que o preconceito e a discriminação são marcas que produzem certos distanciamentos entre as pessoas e os grupos, instituições e organizações produtoras consequente de exclusão de toda ordem, o que acrescentamos, que tais bases e processos acabam sendo naturalizados não apenas quando estes tem a possibilidade de fazer uma reflexão sobre seu fazer, mas também as naturalizam na sua práxis, quando não fazem. Podemos explicar tal processo, na educação, pela falta de preparo psicológico/formação, aliado ao medo da infecção que pode ser apresentado por várias origens, uma delas a própria representação social de uma doença - afeta negativamente tanto a população quanto os mais diversos profissionais que tratam desse assunto, asseverando os modos de exclusão dos indivíduos em todos os espaços.

Minimizar as dificuldades ou imputá-las deste modo àqueles que as vivenciam, é criar um obstáculo ao conhecimento rigoroso ao problema dos estabelecimentos escolares, é contribuir para desmoralização daqueles cujas condições (econômicas, físicas e materiais) para o exercício da sua profissão estão 


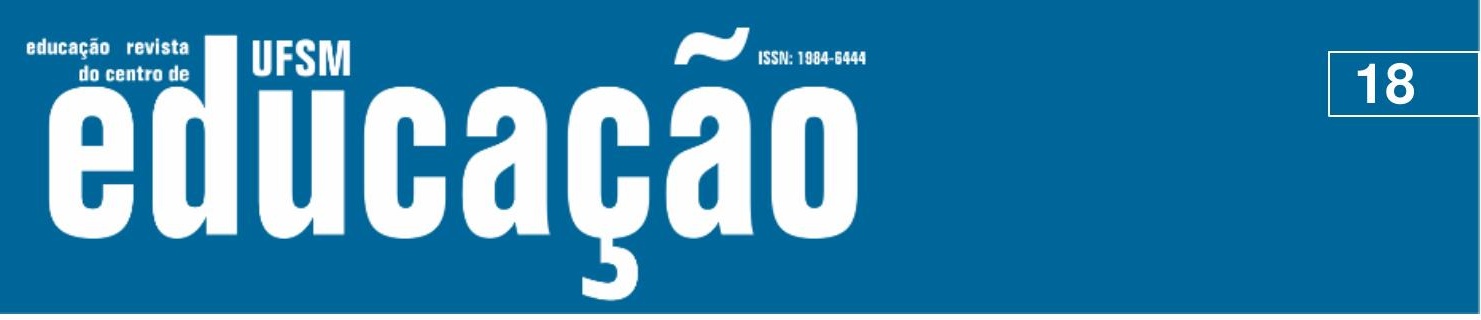

ISSN: 1984-6444 | http://dx.doi.org/10.5902/1984644440327

cada vez mais deterioradas, com agravos na sua formação continuada, implica incluir as condições de vida e trabalho na sua trajetória formativa.

Significa dizer que, o professor hoje, no exercício da sua profissão vê-se mergulhado em um misto de problemas em condições heterogêneas que variam muito entre as instituições de educação e saúde. Principalmente aqueles que atuam em espaços mais afetados, nas periferias, em áreas vulneráveis (acrescenta-se aí o hospital por sua complexidade), vivenciam tanto pior as dificuldades que encontram, porque o insuficiente conhecimento dessas causas deixa aberta a possibilidade de que seja a eles (professores) dirigida a responsabilidade e a culpa por muitos problemas a serem enfrentados na escola como maior desafio desse século: o da escolarização.

Podemos então assinalar que a vida social das crianças e dos adolescentes é atravessada por processos nos quais estão circunstanciadas às produções das díades: normal/patológico, saúde/doença, sucesso/fracasso, como categoria que distinguem, no plano social, o que é prescrito ou aceito daquilo que é proscrito ou recusado, do mesmo modo que reproduzem as marcas (in)visibilizadoras da condição crônica dos alunos na escola e em outros espaços de sua convivência. Isso demonstra, por si só, que a relação entre o discurso e a estrutura social tem natureza dialética, resultando do contraponto entre a determinação do discurso e sua construção social. Assim, o discurso é reflexo de uma realidade mais profunda, e é representado de forma idealizada como fonte social.

Por fim, ao anunciarmos tanto as marcas que (in)visibilizam a condição de crianças e adolescentes com doença crônica na escola, identificamos também, as que produzem (in)visibibidade do professor em outras condições, pois o sistema das instituições ou das organizações são componente, por um lado, de uma complexidade engendrada aos condicionamentos associados a uma classe particular de condições de existência produtoras de habitus ${ }^{4}$, sistemas de disposições duráveis e transponíveis, estruturas estruturadas predispostas a funcionar como estruturas estruturantes e, por outro, ela, a complexidade se choca com estruturas com uma parte de incerteza, tanto daquelas inscritas nos limites do nosso entendimento quanto daquelas inscritas nos fenômenos sociais. 


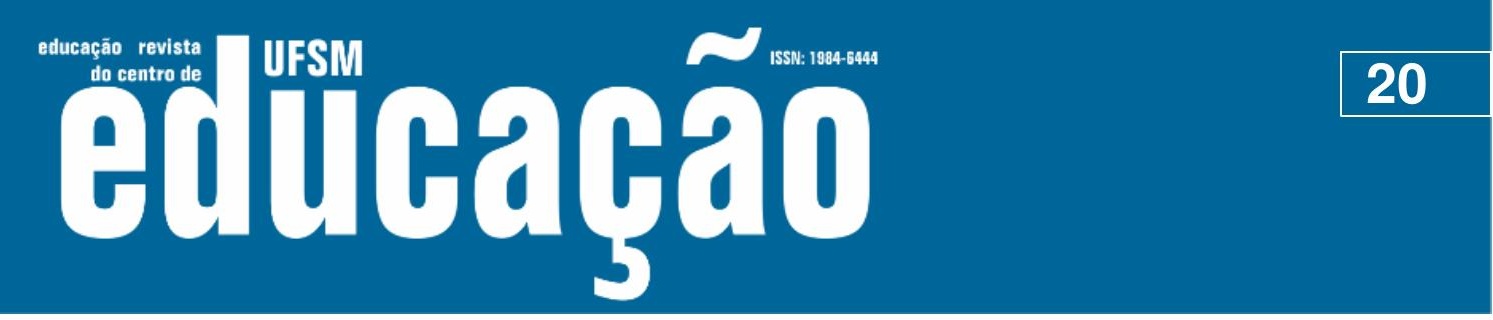

ISSN: 1984-6444 | http://dx.doi.org/10.5902/1984644440327

CECCIM, Ricardo Burg; CARVALHO, Paulo Roberto Antonacci (Org.) Criança hospitalizada: atenção integral como escuta à vida. Porto Alegre: Editora da Universidade Federal do Rio Grande do Sul, 1997.

COVIC, Amália Neide; OLIVEIRA, Fabiana Aparecida de Melo. $\mathbf{O}$ aluno gravemente enfermo. - São Paulo: Cortez. 2011.

HOLANDA. Eliane Rolim de; Doença crônica na infância e o desafio do processo de escolarização: percepção da família. Dissertação. Programa de Pós-Graduação em. Enfermagem da Universidade Federal da Paraíba, 2008

HOLANDA,Eliane Rolim de; COLLET, Neusa. As dificuldades da escolarização da criança com doença crônica no contexto hospitalar. Rev Esc Enferm USP 2011; 45(2):381-9

MARIOTTI, Humberto. As paixões do Ego: complexidade, política e solidariedade. São Paulo: Palas Athena, 2000.

MORIN, Edgar. Os sete saberes necessários à educação do futuro. Trad. Catarina Eleonora F. da Silva; revisão técnica: Edgard de Assis Carvalho. 2. ed. São Paulo: Cortez: Brasília, DF: UNESCO, 2000.

MORIN, Edgar. Educar na era planetária: o pensamento complexo como método de aprendizagem no erro e na incerteza humana. Elaborado pela Unesco por Edgar Morim, Emilio Roger Ciurana, Raúl Domingo Motta; tradução: Sandra Trabucco Valenzuela; revisão técnica da tradução Edgard de Assis Carvalho. São Paulo: Cortez, Brasília, DF; UNESCO, 2003.

MORIN, Edgar. Ensinar a viver: manifesto para mudar a educação. Trad. Edgard de Assis Carvalho e Mariza Perassi Bosco. Porto Alegre: Sulina, 2015.

NONOSE, Eliana Roldão dos Santos. Doenças crônicas na escola: um estudo das necessidades dos alunos. Dissertação. Faculdade de Filosofia e Ciências da Universidade Estadual Paulista Júlio de Mesquita Filho. Marília São Paulo, 2009.

ROSS, Paulo Ricardo. Educação Inclusiva: da ideologia às possibilidades e limites concretos. Ponto de Vista. V2. n 2. Janeiro/dezembro, 2000.

RUSH, Fred (Org).Teoria Crítica. Tradução Beatriz Katinky,, ReginaAndrès Rebollo. Aparecida, SP; Ideias \&Letras, 2008.

SILVA, Maria das Graças Nascimento. Doenças crônicas na infância: Conceito, prevalência, e repercussões emocionais. Revista de Pediatria do Ceará, vol. 2, $\mathrm{n}^{\circ}$ 2. 2001.

SNYDERS, Georges. Escola, Classe e Luta de Classes. Tradução Leila Prado São Paulo: Centauro, 2005. 


\section{educação revista IFSM \\ 7 15SN: 1984-6444

ISSN: 1984-6444 | http://dx.doi.org/10.5902/1984644440327

TARDIF, Maurice; LESSARD, Claude. 0 trabalho docente: elementos para uma teoria da docência como profissão de interações humanas. Tradução de João Batista Kreuch. 3 ${ }^{\underline{a}}$ Ed. - Petropólis, RJ: Vozes, 2007.

\section{Correspondência}

Francisca Maria Sousa - Secretaria de Educação do Estado do Piauí - Av. Pedro Freitas, S/N - Bloco D/F - Centro Administrativo, CEP 64.018-900, Teresina, Piauí, Brasil.

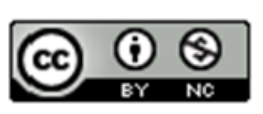

This work is licensed under a Creative Commons Attribution-NonCommercial 4.0 International (CC BY-NC 4.0)

\section{Notas}

\footnotetext{
1 Classe Hospitalar é a nomeação dada pelo Ministério da Educação, muito embora alguns autores como Fonseca, Muggiati e Matos defendam outras terminologias como Pedagogia Hospitalar, Hospitalização Escolarizada, Atendimento Escolar no Ambiente Hospitalar. Neste trabalho optamos pela o uso do termo Classe Hospitalar, mais comumente usado, visto que este nos atende na compreensão do atendimento pedagógicoeducacional de crianças, adolescentes, jovens e adultos hospitalizados na manutenção dos vínculos de sua escolarização.

${ }^{2}$ Em sua vigésima Sétima Assembleia Ordinária, considerando o disposto no Art. $3^{\circ}$ da lei 8.242, de 12 de outubro de 1991, resolve aprovar o texto elaborado pela Sociedade Brasileira de Pediatria (SBP) a Resolução de $\mathrm{N}^{\circ} 41$ em 13 de outubro de 1995, que consta de vinte direitos concernentes às crianças e adolescentes hospitalizados. Dentre os vinte destaca-se o de $\mathrm{n}^{\circ}$ 9, que faz referência ao "direito a desfrutar de alguma forma de recreação, programas de educação para a saúde, acompanhamento do curriculum escolar, durante sua permanência hospitalar." (grifos nossos).
}

3 Acessado em 12.11. 2018. Disponível: http://www2.camara.leg.br/legin/fed/lei/2018/lei-13716-24-setembro2018-787190-publicacaooriginal-156470-pl.html

${ }^{4}$ BOURDIEU (2009). 